\title{
FEM STUDY OF INTERNAL STRESSES EVOLUTION IN PRESTRESSING STRANDS
}

\author{
A. G. Korchunov ${ }^{1}$, E. M. Medvedeva1 ${ }^{\text {, P. V. Ivekeeva1 }}$, D. V. Konstantinov ${ }^{1}$ \\ ${ }^{1}$ Nosov Magnitogorsk State Technical University (Magnitogorsk, Russia) \\ E-mail: international@magtu.ru; fekla_med@mail.ru; fufest01@mail.ru; magstu.international@gmail.com
}

\begin{tabular}{|c|c|}
\hline AUTHOR'S INFO & A B S T RACT \\
\hline $\begin{array}{l}\text { Korchunov A. G., Dr. Eng., } \\
\text { Prof., Vice-Rector on Interna- } \\
\text { tional Affairs, } \\
\text { Medvedeva E. M., Post-graduate } \\
\text { Student, } \\
\text { Ivekeeva P. V., Post-graduate } \\
\text { Student, } \\
\text { Konstantinov D. V., Cand. Eng. }\end{array}$ & $\begin{array}{l}\text { This paper describes the results of modeling when the processes of stranding, reduction, straightening and ther- } \\
\text { mo-mechanical treatment (TMT) of prestressing strands were simulated with the help of finite-element method. } \\
\text { The distribution of residual stresses used in the simulation models refers to the stresses created at the preliminary } \\
\text { stage of wire drawing. The simulation study looked at the effect of thermo-mechanical treatment on the inter- } \\
\text { nal wire stresses: residual stresses resultant from the drawing process and further stranding stresses. All studied } \\
\text { methods demonstrated a positive effect not only in terms of eliminating internal stresses, but also from the point } \\
\text { of view of their redistribution. Reduction of a strand in a solid tool at the ratios of } 1-3 \% \text { allows to create tensile } \\
\text { stresses at the surface of the wire and retain compressive stresses in its core. Straightening in a 5-roller group } \\
\text { helped reach a double relaxation in outer wires. TMT, a process combining different physical effects, enabled to }\end{array}$ \\
\hline $\begin{array}{l}\text { Key words: } \\
\text { prestressing strand, wire, draw- } \\
\text { ing, thermo-mechanical treat- } \\
\text { ment, finite-element modeling, } \\
\text { residual stresses, internal stresses, } \\
\text { stranding, straightening. }\end{array}$ & $\begin{array}{l}\text { control within a broad range the redistribution of residual stresses in steel that was subjected to prior drawing at } \\
\text { high deformation ratios. Such residual stresses occur as a result of stranding stresses that accompany the strand- } \\
\text { ing operation and can affect the geometry of the strand. The study showed that tension as a TMT parameter plays } \\
\text { a greater role in the elimination of longitudinal residual stresses. That's why, at the minimum tension, almost } \\
\text { no redistribution of residual stresses occur either in the central or in the near-surface layers irrespective of the } \\
\text { TMT temperature regime applied. However, when the tension exceeding } 70 \mathrm{kN} \text { is applied at the temperatures of } \\
380-400{ }^{\circ} \mathrm{C} \text {, the central and surface residual stresses balance off in the wire or almost disappear. }\end{array}$ \\
\hline
\end{tabular}

\section{Introduction}

Most of high value-added steel products have a complex geometry (e.g. bolts, nuts, etc.) or consist of multiple components (strands, meshes, etc.). As the products of the metalware industry often find application in construction and design engineering and, consequently, they have to deal with complex loading patterns, it becomes crucial to understand how each processing stage contributes to the performance and processability of the final product.

Prestressing strands designed for prestressed reinforced concrete structures would serve as an excellent example. Application of such prestressing strands helps significantly reduce the cost of structures while enhancing their quality [1]:

- Through heat treatment, the wire rod acquires the desired initial microstructure;

- Multiple drawing helps build the geometry, stressstrain state and microstructure in the process wire;

- The operations of stranding and straightening and a special thermo-mechanical treatment (TMT) regime produce an effect on each wire and the overall strand changing their stress-strain state.

Specific features related to the production and application of prestressing strands for prestressed structures are the subject of numerous research papers and experimental studies [2-12]. The main parameters that define the final properties include the microstructure of steel and internal stresses. They dictate the ultimate strength and relaxation resistance. If it can be relatively easy to gradually build a microstructure through successive process stages by means of experimental and laboratory studies [13], it would be better to use computer simulation software to predict the residual stresses resultant from multi-stage processes involved in the wire production.

This research aimed to conduct an FEM study in order to understand how internal stresses tend to gradually build up in prestressing strands under production and how different TMT modes influence their distribution.

\section{Materials and methods of research}

This paper examines a 7-wire prestressing strand with the diameter of $12.5 \mathrm{~mm}$ and the strength of $1850 \mathrm{MPa}$ made of pearlitic steel. The chemical composition and mechanical properties of the wire after drawing are given in Table 1. The prestressing strand was obtained with the help of the following production operations: patenting; surface preparation; multiple cold drawing (from initial diameter $12 \mathrm{~mm}$ to final diameter $4.1-4.3 \mathrm{~mm}$ ), stranding, straightening, and thermo-mechanical treatment in a stabilization line.

As the wires for prestressing strands are normally drawn at high deformation rates reaching $88-90 \%$, this inevitably creates residual stresses, which affect both the mechanical properties and performance of the final strand, as well as the stranding consistency [13-20]. That's why analysis of the 7-wire prestressing strand production process should be based on evaluation of absolute

\begin{tabular}{|c|c|c|c|c|c|c|}
\hline C & $\mathrm{Mn}$ & $\mathrm{Si}$ & $\mathrm{Cr}$ & $\mathrm{Ni}$ & V & $\begin{array}{c}\text { Tensile strength } \\
\text { after drawing } \sigma_{\mathrm{B}}, \mathrm{MPa}\end{array}$ \\
\hline 0.80 & 0.48 & 0.28 & 0.05 & 0.02 & 0.11 & 2,000 \\
\hline
\end{tabular}


residual stresses and their distribution since they are residual stresses that mostly determine the stress-strain state of the strand during stranding. To these, stranding stresses are added that occur in a wire rope stranding machine.

The drawing process preceding the straightening, stranding and TMT operations was described and examined by means of full-scale experiment and multiscale modelling in the paper [21]. The conventional TMT temperature range is $360-400^{\circ} \mathrm{C}$. Considering the conventionally applied tension, the mechanical properties resultant from the drawing process and the strand, the tension applied varied in the range of $(58 \div 82) \mathrm{kN}$. The lay pitch was $200 \mathrm{~mm}$.

Three models were built to analyze how each processing stage changes the internal stresses:

1. Stranding and reduction model for a 7 -wire strand: A strand is spun to the desired pitch; it is then reduced in a solid tool at the reduction rates of 1,2 and $3 \%$.

2. Straightening model: A strand is spun to the desired pitch and it is then drawn through a group of five horizontal $100 \mathrm{~mm}$ rollers with the groove depth of $8 \mathrm{~mm}$ and depression of $5 \mathrm{~mm}$.

3. Stranding and TMT model for a 7-wire strand: A strand is spun to the desired pitch; it is then heated to the specified temperature within a given range; one end is put under tension; the tension and the heat are removed at the same time.

The same post-drawing distribution of the residual stresses was used for the initial state in all the models as the one examined and verified in the paper [21].

\section{Results of modeling}

\section{Strand reduction model}

Use of solid tools during stranding in wire closing machines may improve the stress state of the strand, create good surface conditions and a good stress state and raise the diameter-related accuracy of the strand while maintaining the interwire gap. At the same time, it is crucial to choose the right reduction modes. The initial reduction stages, which correspond to the reduction in dies, are associated with a non-uniform stress state with a great share of tensile stresses, which impacts the plasticity of steel.

The conventionally applied reduction range is $1-3 \%$. A $4 \%$ or a higher reduction ratio applied would compromise the power efficiency of the stranding process and affect the mechanical properties of steel. To account for residual stresses, the sections of the wires to be stranded together would be divided into areas with the corresponding axial residual stresses measured after wire drawing operation.

The von Mises stress distribution in all the three reduction modes (Fig. 1) remained even in the range of 300 to $600 \mathrm{MPa}$, whereas in the initial state, i.e. after stranding, the stress state was extremely uneven demonstrating a considerable difference between surface and core stresses.

The reduction ratios of 2 and 3\% appear to be comparable in terms of radial strain distribution, however they were found to be more favourable compared with

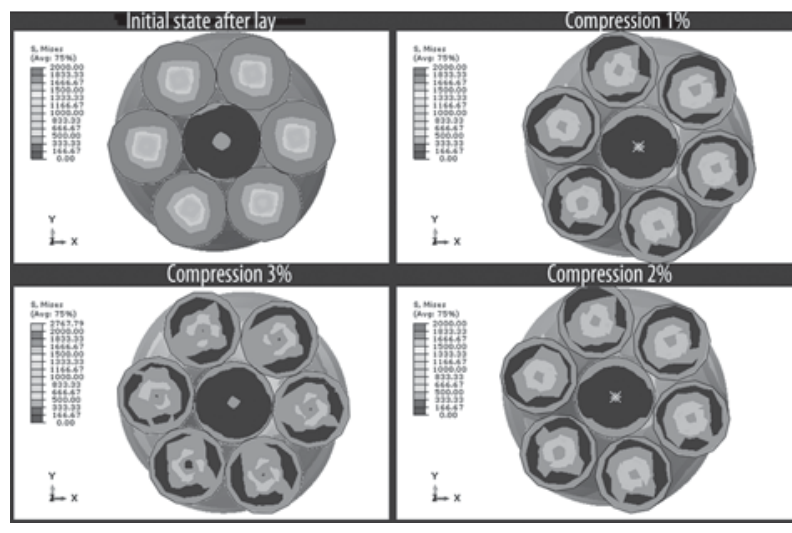

Fig. 1. Von Mises stress distribution

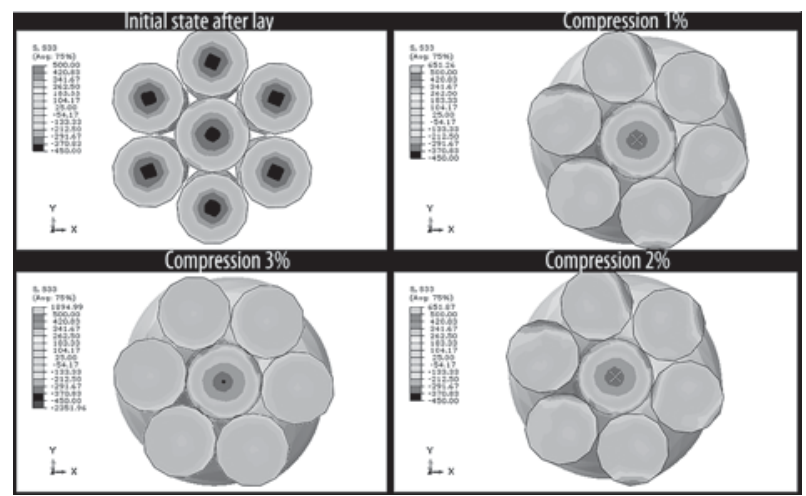

Fig. 2. Longitudinal residual stress distribution

the $1 \%$ reduction mode. In these modes, the wires have symmetrical compression strains localized at the surface that enhance the mechanical properties of steel. A 3\% reduction mode is most beneficial in terms of longitudinal residual stress distribution (Fig. 2) associated with minimized tensile residual stresses at the surface and maximum compression stresses retained in the core.

Correspondingly, the most favourable stress-strain state is obtained when the reduction ratio is at least $2 \%$.

\section{Straightening model}

Comparison of the distributions of the von Mises stresses (Fig. 3) and longitudinal stresses (Fig. 4), which are of great relevance for the production of strands, shows that straightening of a $12.5 \mathrm{~mm}$ strand with up to $5 \mathrm{~mm}$ depression in one group of rollers can result in considerable changes in the stress state of the strand (mainly, of the outer wires). Thus, the longitudinal stresses in the outer wires reduce by 1.7-2 times, and in separate wires they can reach near-zero values. At the same time, the von Mises stresses in all outer wires see a 1.5-2 times drop, which makes the strand less prone to untwisting and produces an overall relaxation effect. However, a bigger depression may affect the geometry of the strand and result in a higher pulling force. Besides, a bigger depression will inevitably lead to a bigger contact arc between the strand and each roller leading to roll wear. That's why the best solution in this case would be to use a few alternating groups of straightening rollers (horizontal and vertical) 


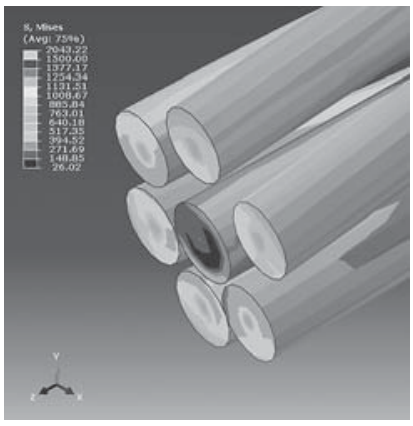

Fig. 3. Von Mises stresses in the exit section

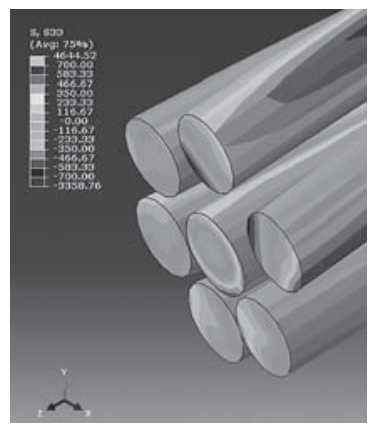

Fig. 4. Longitudinal stresses in the strand crosssection

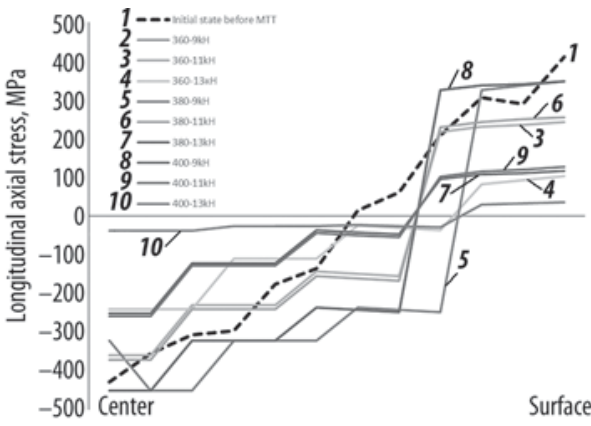

Fig. 7. Redistribution of longitudinal residual stresses following various TMT modes (tension values are indicated separately for central wire)

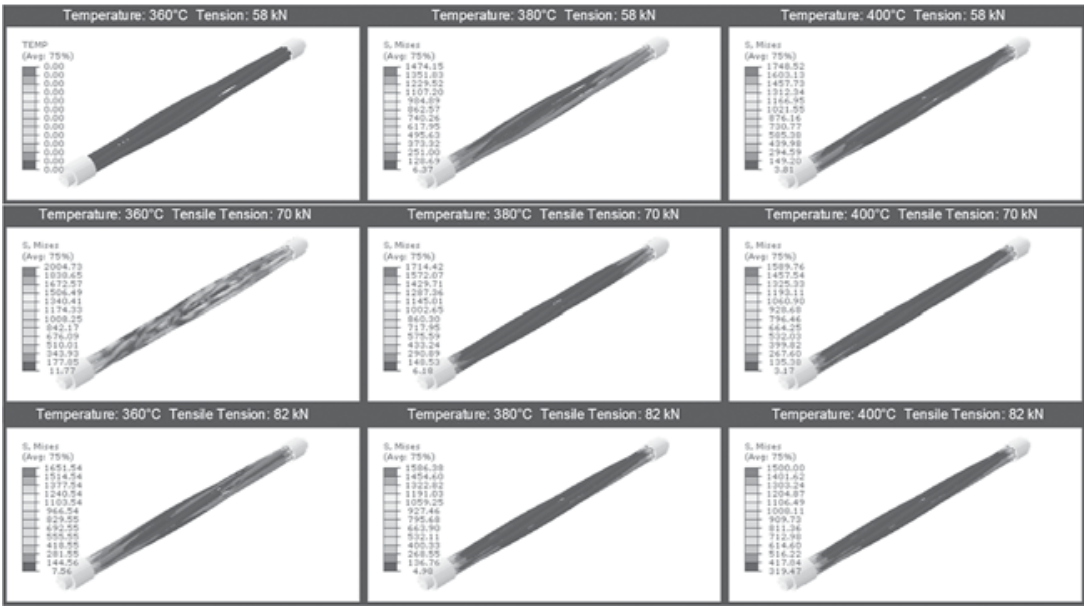

Fig. 5. Computer models of strands after various TMT modes (the von Mises stress)

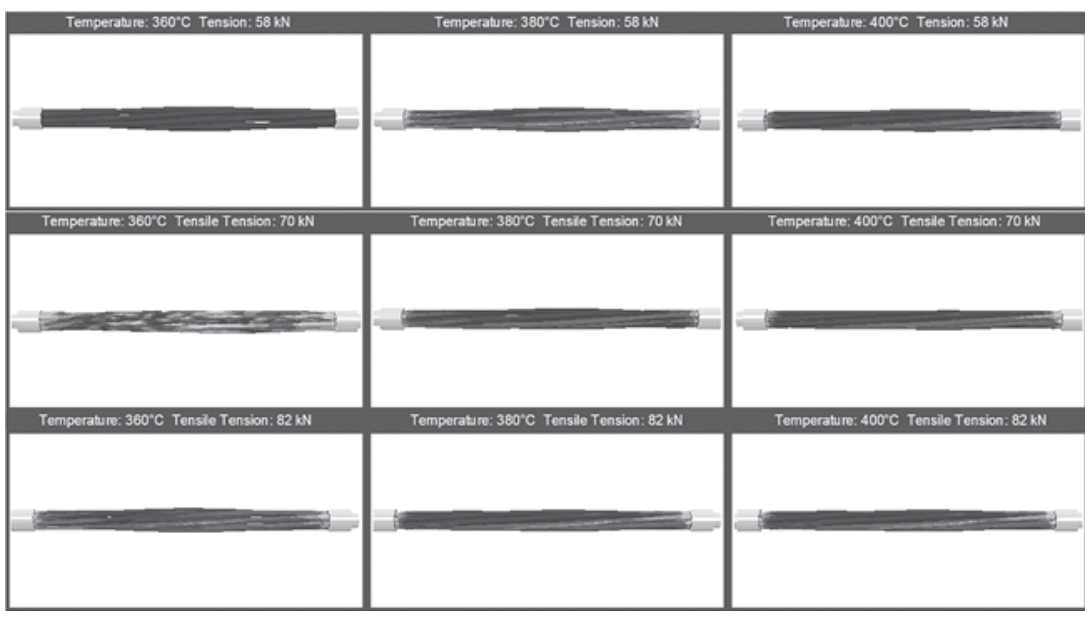

Fig. 6. Computer models of strands after various TMT modes (the stranding result is retained after $\mathrm{TMT}$ )

while maintaining the depression on each group within $5 \mathrm{~mm}$ for a $12.5 \mathrm{~mm}$ strand.

\section{TMT model}

Fig. 5 shows a stress-strain state model of the strand after TMT. Fig. 6 shows strand models following different TMT modes enabling to analyze how much the geometry of the strand gets corrupted after the load is released. As one can see from the results obtained, at the minimum temperature of $360{ }^{\circ} \mathrm{C}$ or at the minimum tension of $58 \mathrm{kN}$ the strand is highly likely to deform (see Fig. 5). But starting from the tension of $70 \mathrm{kN}$ and the temperature exceeding $360^{\circ} \mathrm{C}$, the TMT process helps to almost completely remove stranding stresses that want to loosen the strand.

The distribution of longitudinal residual stresses in the central wire following TMT is shown in Fig. 7 and Fig. 8.

As is demonstrated in Fig. 7 and 8, tension plays a greater role in the elimination of longitudinal residual stresses. That's why, at the minimum tension, almost no redistribution of residual stresses occur either in the central, or in the near-surface layers irrespective of the TMT temperature regime applied. At the same time the tension of $70 \mathrm{kN}$ reached at the temperatures of 360 $380^{\circ} \mathrm{C}$ creates a borderline state in the central wire, and reaching its triggers an intensive redistribution process. In terms of residual stresses and their elimination after drawing, the most effective modes include the tension of $82 \mathrm{kN}$ at any of the studied temperatures and the tension of $70 \mathrm{kN}$ at the temperature of $400{ }^{\circ} \mathrm{C}$. In the above modes, the central and surface residual stresses balance off in the wire or almost disappear.

\section{Conclusion}

Absolute residual stresses and their distribution in the wire, which is used in 7-wire strands and produced by prior drawing, determine the performance of the final product. TMT, a process combining different physical effects, enables to control within a broad range the redistribution of residual stresses in steel that was subjected to prior drawing at high deformation ratios. Such residual stresses occur as a result of stranding stresses that accompany the strand- 


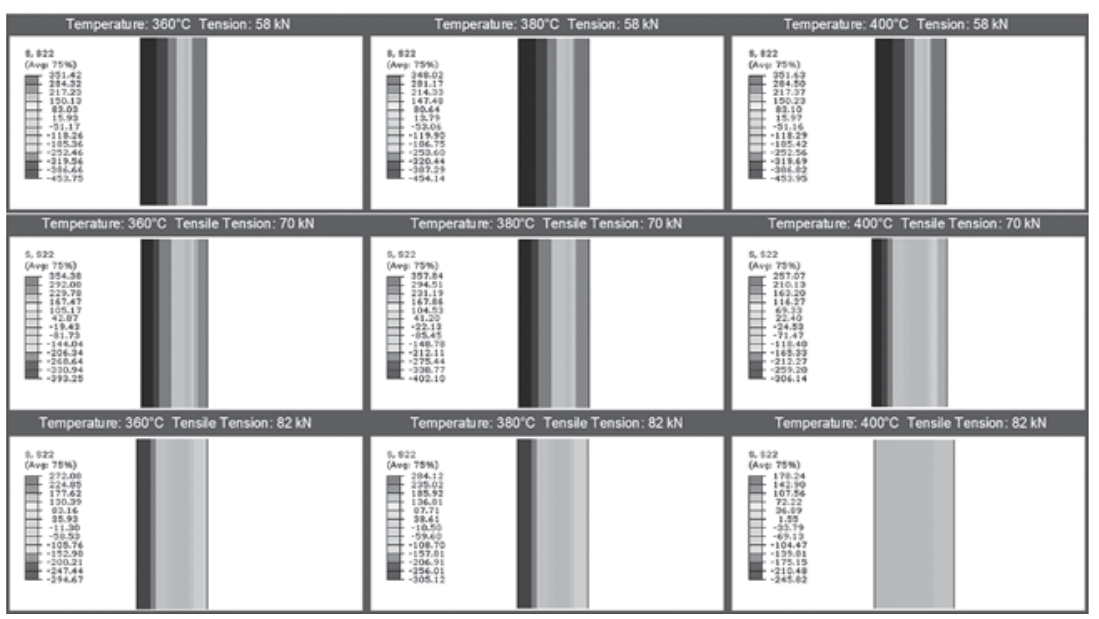

Fig. 8. Longitudinal residual stresses in the central wire after TMT (tension values are indicated separately for full strand)

ing operation and can affect the geometry of the strand. Drawing to $80 \%$ strain creates compressive residual stresses of 1,100-1,200 MPa in the central layers of the wire, which is comparable to $68 \%$ of the ultimate strength of the wire. At the same time, the residual stresses at the surface of the wire are in fact tension stresses equating to $450-500 \mathrm{MPa}$, which corresponds to $25 \%$ of the ultimate strength of the wire used for the strand in view. A combination of the tension of $82 \mathrm{kN}$ or $70 \mathrm{kN}$ with the temperature range of $360-380{ }^{\circ} \mathrm{C}$ helps achieve a double reduction of residual stresses both in the central and surface layers of the wire. A complete elimination of residual stresses may become achievable when raising the temperature to $400{ }^{\circ} \mathrm{C}$ while maintaining the same tension. Application of a lower tension did not prove to influence in any way the distribution of residual stresses. Stranding stresses, which, when high, can change the lay pitch and affect the geometry of the strand, can only be completely removed when the tension of $82 \mathrm{kN}$ or $70 \mathrm{kN}$ is applied in the temperature range of $380-400^{\circ} \mathrm{C}$. In all the other cases stranding stresses lead to loosening of the strand geometry.

This research was carried out under the Decree No. 220 dated 9th April 2010 of the Government of the Russian Federation (Contract No. 075-15-2019-869 dated 12 $2^{\text {th }}$ May 2019) and was funded by the Russian Science Foundation (Project No. 20-69-46042 dated 20th May 2020) and by the Russian Ministry of Education and Science with the goal of developing high-tech production (contract nos. 02. G25.31.078, December 1, 2015; and MK204895, July 27, 2015).

\section{REFERENCES}

1. Madatyan S. A. Current requirements to prestressing steel. Beton i zhelezobeton. 2005. No. 1. pp. 8-10.

2. Egorov V. D., Voronina V. S. Production of stabilized prestressing strands. Stal. 1983. No. 3. pp. 65-66.

3. Costello G. A. Theory of wire rope. Second edition. New York: Springer, 1997. 123 p.

4. Feyrer K. Wire ropes: tension, endurance, reliability. Berlin Heidelberg - New York: Springer, 2007. 322 p.

5. Jacinto L., Pipa M., Oliveira Santos L. Probabilistic models for mechanical properties of prestressing strands. Construction and Building Materials. 2012. Vol. 36. pp. 84-89.
6. Aytaç Onur Yu. Experimental and theoretical investigation of prestressing steel strand subjected to tensile load. International Journal of Mechanical Sciences. 2016. Vol. 118. pp. 91-100.

7. Obaydullah M., Zamin Jumaat M., Johnson Alengaram U., Mahfuz ud Darain Kh., Nazmul Huda Md., Akter Hosen Md. Prestressing of NSM steel strands to enhance the structural performance of prestressed concrete beams. Construction and Building Materials. 2016. Vol. 129. pp. 289-301.

8. Mikhailov K. V. Challenges faced by the domestic construction science in the area of prestressed reinforced concrete structures. Beton i zhelezobeton. 2004. No. 2. pp. 3-5.

9. Chukin M. V., Gun G. S., Korchunov A. G., Polyakova M. A. Prospects of production of high-strength steel reinforced bars made of high-carbon steels. Chernye Metally. 2012. No. 12. pp. 8-16.

10. Chabbi L. Simulation of microstructure and mechanical properties in section rolling. Chernye Metally. 2017. No. 9. pp. 57-62.

11. Korchunov A. G., Gun G. S., Shiryaev O. P., Pivovarova K. G. Study of structural transformation of hot-rolled carbon billets for high-strength ropes for responsible applications via the method of thermal analysis. CIS Iron and Steel Review. 2017. Vol. 13. pp. 38-40.

12. Korchunov A. G., Polyakova M. A., Konstantinov D. V., Dabalá M. Mechanical properties of prestressing strands and how they tend to change under thermo-mechanical treatment. CIS Iron and Steel Review. 2019. Vol. 18. pp. 14-19.

13. Caballero L., Atienza J. M., Elices M. Thermo-mechanical treatment effects on stress relaxation and hydrogen embrittlement of cold-drawn eutectoid steels. Metals and Materials International. 2011. Vol. 17. No. 6. pp. 899-910.

14. Atienza J. M., Elices M., Ruiz-Hervias J., Caballero L., Valiente A. Residual Stresses and Durability in Cold Drawn Eutectoid Steel Wires. Metals and Materials International. 2007. Vol. 13. No. 2. pp. 139-143.

15. Atienza J. M., Elices M. Influence of residual stresses in the stress relaxation of cold drawn wires. Materials and Structures / Materiaux et Constructions. 2004. Vol. 37. June. pp. 301-304.

16. Elices M. Influence of residual stresses in the performance of cold-drawn pearlitic wires. Journal Of Materials Science. 2004. Vol. 39. pp. 3889-3899.

17. Atienza J. M., Ruiz-Hervias J., Elices M. The Role of Residual Stresses in the Performance and Durability of Prestressing Steel Wires. Experimental Mechanics. 2012. Vol. 52. pp. 881-893.

18. Atienza J. M., Ruiz-Hervias J., Martinez-Perez M. L., Mompean F. J., Garcia-Hernandez M., Elices M. Residual stresses in cold drawn pearlitic rods. Scripta Materialia. 2005. Vol. 52. pp. $1223-1228$.

19. Martinez-Perez M. L., Mompean F. J., Ruiz-Hervias J., Borlado C. R., Atienza J. M., Garcia-Hernandez M., Elices M., Gil-Sevillano J., Ru Lin Peng, Buslaps T. Residual stress profiling in the ferrite and cementite phases of cold-drawn steel rods by synchrotron X-ray and neutron diffraction. Acta Materialia. 2004. Vol. 52. pp. 5303-5313.

20. Zheng Wenzhong, Hu Qiong, Zhang Haoyu. Experimental research on the mechanical property of prestressing steel wire during and after heating. Frontiers of Structural and Civil Engineering. China 2007.

21. Konstantinov D. V., Korchunov A. G., Zaitseva M. V., Shiryaev O. P., Emaleeva D. G. Macro- and Micromechanics of Pearlitic-Steel Deformation in Multistage Wire Production. Steel in Translation. 2018. Vol. 48. pp. 458-462. 